\title{
ПРОБЛЕМА МОББИНГА В СОВРЕМЕННОМ ПРОИЗВОДСТВЕННОМ КОЛЛЕКТИВЕ
}

\section{THE PROBLEM OF MOBBING IN A MODERN PRODUCTION TEAM \\ T. Kurbatskaya \\ D. Polyakova}

Summary: The article discusses the definition of «mobbing», reflects the existing types of mobbing, analyzes the causes of mobbing, considers methods to protect employees from the manifestation of mobbing.

Keywords: mobbing; mobber; personnel Management.
$\mathrm{M}$ оббинг (от англ. mobbing - притеснять и преследовать кого-либо, кому-то грубить, нападать или придираться) это процесс умышленного психологического воздействия на человека с целью его последующего увольнения.

Моббинг может проявляться в трудовых коллективах на работе, в учебных группах, в школе и даже в армии в виде дедовщины. Моббинг может проявляться многообразно, и поэтому его представляют различными классификациями. Различают внутригрупповой, межгрупповой и сэндвич-моббинг [3].

Внутригрупповой моббинг чаще всего применяют по отношению к новичкам более «старые» по продолжительности работы в организации сотрудники.

Межгрупповой возникает в том случае, если требуется освободить место для продвижения кого-то по службе или руководитель хочет избавиться от сотрудника.

Сэндвич-моббинг - промежуточный тип моббингового поведения. Самый жесткий вид моббинга, когда нападки идут отовсюду: и со стороны подчиненных, и со стороны руководства.

По признаку осознания своих целей исполнителем моббинг может быть сознательный и неосознанный.

Сознательный моббинг характеризуется целенаправленностью действий. В этом случае чаще всего речь идет о корыстных мотивах - занять чье-то место, выслужиться перед начальством.

О неосознанном, или стихийном моббинге можно говорить, когда субъект моббинга не отдает себе отче-

\author{
Курбацкая Татьяна Борисовна \\ к.nсх.н., дочент, Российская открытая академия \\ транспорта (МИИТ) \\ alterego123@yandex.ru \\ Полякова Диана Валерьевна \\ Российская открытая академия транспорта (МИИТ) \\ DV_1105@mail.ru
}

Аннотация: В статье рассматривается определение «моббинг», отражены существующие виды моббинга, проанализированы причины возникновения моббинга, рассмотрены методы по защите сотрудников от проявления моббинга.

Ключевые слова: моббинг; моббер; управление персоналом.

та в том, что его действия попадают под квалификацию моббинга. В этом случае кто-то из коллег вызывает у него постоянное раздражение, которое сопровождается неуставным поведением. По форме проявления моббинг может быть также лалтентный (объект нападения пытается сдержать натиск мобберов) и открытый. По количеству участников - индивидуальный или груплповой. По характеру протекания - хронический или самовозлрождающийся (выжив одного коллегу, моббер принимается за другого).

При значительном многообразии форм моббинг-действий, наиболее часто на практике встречаются следующие [1]:

- боссинг;
- стаффинг;
- буллинг;

Боссинг - моральное преследование сотрудника руководителем. Как разновидность моббинга боссинг включает такие действия, как подрыв компетенции, критика внешнего вида или возраста, дискредитация родственников, акцентирование внимания на происхождении, перекладывание ответственности за возникающие проблемы , а также личные оскорбления в адрес работника. Руководитель-моббер может использовать свое положение, давать неверные указания, планируя слишком мало времени для выполнения работы или не принимая ее, указывая на «недостатки».

Стаффинг - разновидность моббинга , представляющие собой действия, мешающие руководителю исполнять свои прямые обязанности и дискредитирующие его деятельность. Например, провокационное поведение подчиненных, неисполнение постановлений и приказов руководителя или, наоборот, выполнение заданий 
«строго по инструкции». Также к стаффингу можно отнести подстрекание других сотрудников занять сторону мобберов путем подрыва авторитета руководителя, дискредитации его компетенции, распространения слухов о его личной жизни, физическом и психическом здоровье, а также положении в организации.

Буллинг (workplace bullying) - понятие, введенное английским журналистом Эндрю Адамсом. Характеризует форму психологического насилия, при которой сотрудник или группа подвергаются целенаправленной травле со стороны конкретного лица посредством злонамеренных действий, унижающих их достоинство. Буллинг может быть направлен против жертвы, независимо от ее положения в компании.

Изучая возникновение моббинга, можно выделить причины четырех видов: внешние по отношению к организации (экономические, правовые, социокультурные, историко-этнографические), внутриорганизационные (особенности производства, особенности коллектива, специфика менеджмента), социальные (цели участников моббинга, социальный статус), личностные причины (причины психологического характера, специфические признаки жертвы).

Последствия моббинга для организации - проблемы в развитии и получении доходов. Его игнорирование руководителями неизбежно приведет к непоправимому ухудшению психологического климата в коллективе. Все чаще будут возникать ссоры и конфликты, мешающие слаженной работе, способной обеспечить успех компании и ее прибыль.

Систематические негативные действия по отношению к жертве моббинга вызывают отрицательные эмоции, чувства неуверенности, страх , а это, как правило , влияет на отношение человека к работе, эффективность его труда и на состояние здоровья в целом.

Диагностика моббинг-процессов в организации представляет собой процесс определения и выявления случаев возникновения моббинга среди работников, который выступает как необходимая первая ступень для последующего анализа этого явления [2]. Для диагностики моббинг-процессов в системе межличностных конфликтов среди работников одной из Российских транспортных компаний был применен метод анкетирования. Целью анкетирования работников являлось изучение возникновения моббинг-ситуации в подразделениях компании.

По результатам анкетирования самыми выраженными факторами были выявлены: невозможность планирования обучения/повышения квалификации, создание стрессовой обстановки, перегрузки.
Можно сделать вывод, что руководством выбрана директивная тактика управления персоналом в данной организации, в приоритете выполнение задач любыми способами, не взирая на человеческие ресурсы. Руководителю не интерсно повышение квалификации и развитие своего персонала, по его мнению, эта лишняя трата времени и денег для организации. HR специалист должен принимать необходимые меры для выхода из уже существующего моббинг-конфликта. Для защиты сотрудников от проявления моббинга в производственном коллективе необходимо проведение следующих мероприятий:

1. Работа с руководством. Антимоббинговая политика должна начинаться с высшего менеджмента, и выражаться в информировании и подготовке лиц на руководящих должностях.

2. Коучинг. Проведение тренингов по борьбе с моббинг явлениями с руководителями и сотрудниками.

3. Разработка руководителем активных и эффективных мер по предотвращению моббинга в организации:

- использование законодательных норм;

- социально-ориентированный менеджмент и организационная политика;

- контроль управленческих решений;

- работа с участниками конфликта: беседа с работником, предупреждения, выговоры, перевод на другое место работы.

4. Привлечение для защиты от моббинга представительных организаций (например, профсоюзов).

В качестве действенных площадок для контактирования с жертвой моббинга они могут:

- проинформировать о последствиях моббинга с точки зрения трудового законодательства;

- помочь в проведении переговоров между «жертвой» и моббером для достижения взаимопонимания;

- помочь в составлении жалобы на моббера;

- помочь в поиске юридической, медицинской помощи;

- реализовывать принятые антимоббинговые решения в организации.

5. Проведение собеседования.

Разговор с целью прекращения моббинга может иметь различные сценарии в зависимости от того, какая цель ставится представителем работодателя и с кем из участников конфликта он будет проходить.

6. Важный этап в защите работника от моббингконфликта - организационные действия по его активной поддержке после того, как действия моббера пресечены. Это психотерапия, помощь группы взаимопомощи и медицинское лечение. Работодатель должен предоставить жертве моббинга необходимую информацию и контактные 
данные. Кроме этого - внимательно наблюдать за поведением коллектива, где отмечены случаи моббинга.

В интересах как руководства, так и сотрудников - не запускать отдельные конфликты в организации до той степени, когда профилактические меры уже не помогают. Профилактика моббинга менее затратна для организации и менее дискомфортна для сотрудников, нежели противодействие текущему конфликту. Однако и те, и другие меры одинаково важны для обеспечения успешной работы.

Bсе эти мероприятия не могут в полной мере защитить сотрудника от проявления моббинга пока не будет правовой базы для привлечения к ответственности моббера [4]. Проведя анализ нормативно-правовой базы, регламентирующей трудовые отношения в Российской Федерации, можем отметить отсутствие понятия «моббинг». На практике доказать, что сотрудник пострадал от моббинг-действий трудно.

\section{ЛИТЕРАТУРА}

1. Бабанов, С.А. Моббинг как психологический террор в трудовом коллективе и его профилактика / С.А. Бабанов // Терапевт. — 2018. — № 10. — C. 49-57

2. Бурьянец, В.А. Моббинг в организации: пути решения проблемы / В.А. Бурьянец // Научный журнал Дискурс. — 2018. — № 4 (18). — C. $108-112$.

3. Дуракова, И.Б. Актуальные проблемы управления персоналом: моббинг Учебное пособие / Москва, 2018.

4. Курсова, О.В. Трудовое право: правовой идеал и правовой вакуум: к вопросу о защите работника от психологического насилия в России / 0.В. Курсова, И.Л. Плужник - Тюмень: Российский журнал правовых исследований, 2019. - 10с

5. Шевараков, А.А. Моббинг в организации / А.А. Шевараков // В сборнике: Юность. Наука. Культура Материалы VI Всероссийской научно-практической конференции. Редколлегия: Г.П. Кулешова [и др.]. — 2019. — С. 61-64.

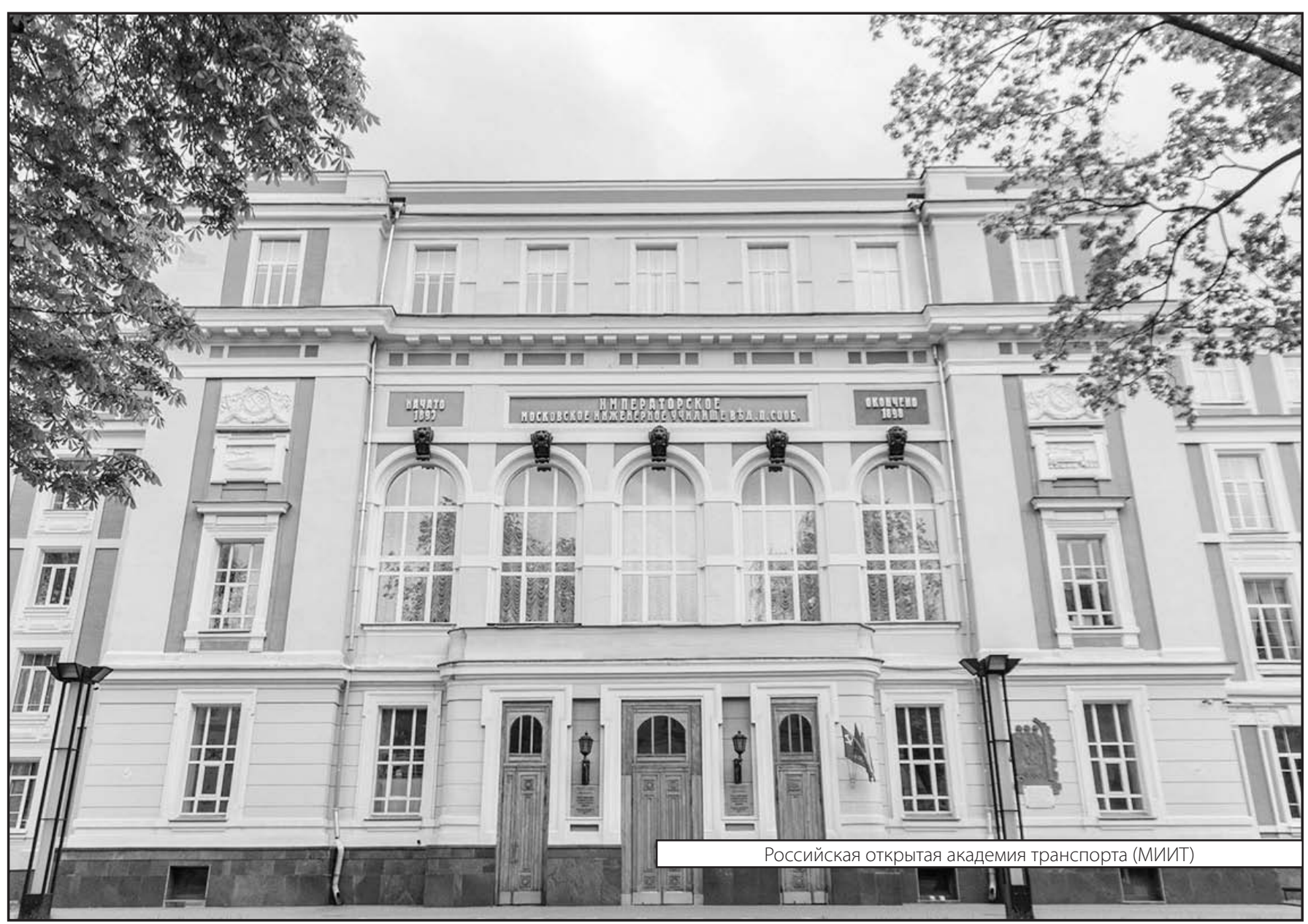

